\title{
Elements of the Prospect Theory in Strategic Investment Games
}

\author{
Marek Jarzęcki, Jacek Mizerka*
}

\begin{abstract}
The article proposes a real option game analysis including elements of prospect theory. Bounded rationality of the competitor is assumed, whose perception is described by value and weighting functions. The problem is illustrated by numerical examples. The article initiates the discussion about the implications of behavioural finance achievements for real option games analysis and shared options valuation.
\end{abstract}

Keywords: real option games, prospect theory, behavioural finance

\section{Introduction}

Traditional valuation methods ignore important aspects of strategic management, namely decision flexibility and competition. Real option games are helpful when these two factors occur. However, taking into account behavioural finance achievements makes it necessary to include in the analysis people's bounded rationality. It is prospect theory that illustrates economic decision making under risk, an area analysed in the real option literature.

This article proposes a real option games analysis including value and probabilities perception described as by Kahnemann and Tversky's (1979) value and weighting functions. The article shows how people's psychological characteristics can influence perceived option values. This kind of bounded rationality should be in turn considered by a fully rational player. The purpose of the article is to present how these psychological aspects can influence payoffs distribution, changing solution to option subgames and, finally, the value of a shared option.

We start with a short presentation of the essence of the real option and option games approaches and illustrate them with a simple numerical example. Next, we propose an option valuation model including elements of prospect theory. Finally we modify the previous example in the prospect theory context, giving up the full rationality assumption. The article ends with a discussion about the consequences of the competitor's bounded rationality for payoffs distribution.

\footnotetext{
* mgr Marek Jarzęcki, Katedra Finansów Przedsiębiorstw, Uniwersytet Ekonomiczny w Poznaniu, al. Niepodległości 10, 61-875 Poznań, e-mail: marek.jarzecki@ue.poznan.pl; dr hab. Jacek Mizerka, prof. UEP, Katedra Finansów Przedsiębiorstw, Uniwersytet Ekonomiczny w Poznaniu, al. Niepodległości 10, 61-875 Poznań, e-mail: jacek.mizerka@ue.poznan.pl.
} 


\section{Real option games - strategic decision flexibility and competition}

The dominating traditional valuation methods based on discounted cash flows treat investment projects as "take it or leave it" decisions, assuming the immediate realization of projects of positive net present value and the irreversible rejection of those of NPV $<0$ ("now or never"). In practice a management investment strategy is dynamic (Smit, Ankum 1993). The real option approach enables us to treat investment decisions as "wait and see" situations, where the sheer possibility of a decision postponement is a source of relevant value (Smit, Trigeorgis 2006).

Thanks to the analogy between investment decisions flexibility and financial options, financial option valuation methods can be used and a firm can be seen as a collection of assets and growth options connected with them (Myers 1977). For example, using the Cox-RossRu-binstein (CRR) model (1979) the value of a real option can be assessed by constructing a hedging portfolio consisting of the underlying instrument and a risk-free loan. Based on the no-arbitrage hypothesis, the option value should be equal to the value of the hedging portfolio.

One of the limitations of the basic real option approach is the assumption of the exclusive possession of the option (proprietary options). In most situations players do not have any legal protection (e.g. patent) that would make them the only holders of the real option. Most real options are shared. The competitor's activity can crucially influence the optimal exercise strategy and therefore also the real option value (Tallon et al. 2002; Zhu, Weyant 2003). A classical real option valuation in these situations proposes using elements of game theory and building real option games models.

Game theory is a general theory of strategic situations (von Neumann, Morgenstern 1944), based on two major assumptions: full rationality and common knowledge. Full rationality means that each player makes only choices maximizing his/her utility. Moreover, the second player knows that the first player is fully rational. The first player knows that the second player knows he/she is rational etc. (common knowledge assumption) (Watson 2001). John Nash (1950) defined the equilibrium in strategic games as a combination of players' strategies where no one is interested in changing his/her strategy. Finding the equilibrium results from each player choosing the best response to his/her competitor's actions. In real option games the equilibrium is found in all moments and states of reality (subgames). Using backward induction, the real potion value is calculated as a function of each player's expected future behaviour (Smit, Ankum 1993; Grenadier 2002).

Thanks to real option games it is possible to take into account three important sources of value of an investment: (1) value of future cash flows resulting from immediate realization of an investment (NPV), (2) value of flexibility connected to active strategic management (time value of the option) and (3) value of strategic interactions in a competitive environment (value assessed by using game theory) (Smit, Trigeorgis 2006). 
Real option game models have some limitations from the point of view of behavioural finance. Especially, it is hardly probable that humans could conduct such a complicated analytical process. Consequently, the 'predictive' power of such models in many cases can be limited, leading to suboptimal decisions. Moreover, the sheer full rationality and common knowledge assumption stays in conflict with the achievements of behavioural finance that indicate numerous sources of people's bounded rationality.

Smit and Trigeorgis (2004) present simple examples of strategic investment games, illustrating the logic that managers should use while evaluating investments when conventional approaches (NPV) are unsuitable. In their example ${ }^{1}$ a high-tech company holds a one-year license (proprietary option) to invest in the commercial production of a new product. It can invest either immediately or after a year, when demand uncertainty will be clarified. The same situation is later analysed allowing for endogenous competition, where part of the total market value can be taken away by a competitive entry (shared option). The incumbent can pre-empt competitive entry in order to avoid competitive value erosion.

The example illustrates an opportunity for a high-tech firm to build a plant to produce a new product. This involves making an expenditure of $\mathrm{I}_{0}=\$ 80 \mathrm{M}$. The investment is possible immediately or after a year. The expected value of future inflows from production is at the beginning equal to $\mathrm{V}_{0}=\$ 100 \mathrm{M}$. After a year, depending on the level of future demand, it can rise to $V_{u}=\$ 180 \mathrm{M}$ or fall to $V_{d}=\$ 80 \mathrm{M}$, with equal probabilities of $p=0.5$.

Considering the situation of endogenous competition, there is a second player, or another similar high tech firm acting on the same market. The option is shared, so both players can invest. In each node of the binominal tree there are four possible situations: (1) both players invest, $(2,3)$ one of them invests and the other waits or (4) neither of the players invests. In situation (1) the players share both benefits and investment expense ${ }^{2}$, in situations (2) and (3) one of the players gets the whole NPV of the project and the other nothing, and in situation (4) both players have the value of the option resulting from the future investment possibility.

\footnotetext{
${ }^{1}$ Smit and Trigeorgis (2004) describe a two-stage strategic investment. The first stage of the decision-making process is linked with the R\&D expenditure of a high-tech firm. It can invest in R\&D in the first place so that it will acquire a proprietary option to commercialize its product in the second stage. For reasons of simplicity, the example presented by Smit and Trigeorgis was simplified for the purposes of the article. Only the second stage of the example, or the commercialization stage, is analysed. Moreover, Smit and Trigeorgis analyse four competitive situations depending on two characteristics: the type of investment (proprietary vs. shared) and the nature of competitive (re) action (contrarian or reciprocating). For reasons of clarity, only one combination of the type of investment and the nature of competitive reaction is analysed: the case of shared strategic benefits when competitors are contrarian. This was chosen because it is the easiest situation: there is no market value reduction and market shares are equal. But more importantly, it results in the same payoffs for both players, allowing for a further better illustration of the influence of a new element - players' perception according to the prospect theory - that will be the only source of differences in player's payoffs. This corresponds with the example of a European option with endogenous competitive reactions presented by Smit and Trigeorgis (2004: 217-254).

${ }^{2}$ Depending on the competitive landscape, the shares can differ. In the chosen case of contrarian competitive reaction, the shares of both players are equal.
} 


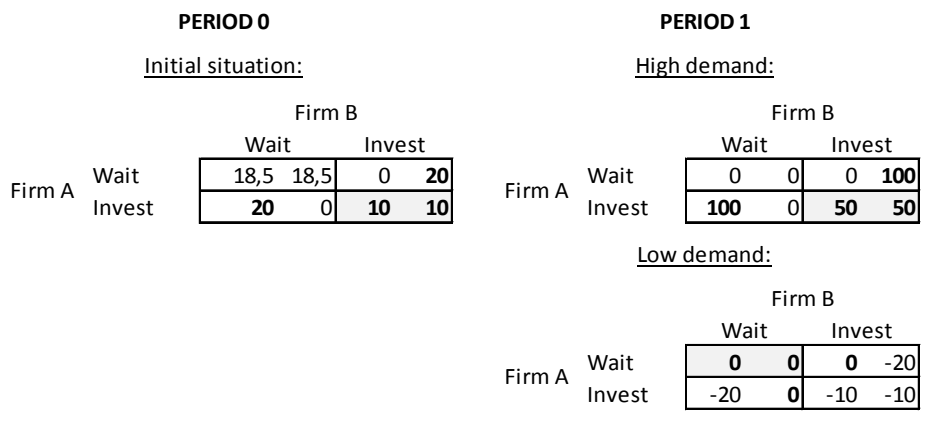

Figure 1. Players' payoffs in the exemplary option game - classical approach

Source: authors' own.

In order to assess the value of the option to invest, the backward induction approach is needed. In the last period (after a year), two levels of benefits are possible: 180 or 60 . The player's payoffs depend on each player's decision about whether to invest. For example, in the case of high demand the benefits from production are equal to 180 . If both players invest, each of them gets $1 / 2 \times 180-1 / 2 \times 80=50$; if one of them invests he/she gets $180-80=100$ and the other nothing; if neither of them invests, nobody gets anything. Analysing the payoffs in both nodes of period 1, Nash equilibriums can be found in each subgame. In the situation of high demand both players should decide to invest, because this would make them indifferent about the other player's decision. In both situations - of the competitor investing and not investing - they would get more (50 or 100 respectively). The alternative (not investing) means no benefits (NPV $=0$ ) for them - only when investing can they achieve a positive NPV value. In the situation of low demand both players should reject the investment because investing would have a negative NPV value for them. As a result, in the case of high demand each player earns 50 , in the case of low demand -0 .

The major difference in period 0 is that if both players wait, they can still invest in the last year, so waiting can have value for them. This value is equal to the value of the option to invest after a year (in period 1). This value has to comply with the result of the games played in the last period, so it depends on the expected future behaviour of both players. In period 0 (now) if both players wait, their option has the value of $18.5(=(0.4 \times 50+0,6 \times 0) /(1+0.08))^{3}$. This value was calculated by using the CRR model. The Nash equilibrium is found in the same way as in the previously described subgames. Both players decide to invest because even if they share the market pie, they will earn some positive value, or more than in the situation where they do not invest $(\mathrm{NPV}=0)$ while their competitor does. On the other hand, the value of waiting (the option value equal to 18.5) is lower than NPV from the independent

\footnotetext{
${ }^{3}$ Risk-free rate of 0.08 is assumed. The arbitrage probability for an increase of the underlying instrument is $0.4=[100 \times(1+0.08)-60] /(180-60)$ (Smit, Trigeorgis 2004).
} 
investment $(\mathrm{NPV}=20)$. The solution to the option game example is pure equilibrium, where each of the players gets the payoff of 10 - the NPV value resulting from simultaneous immediate investment.

\section{Including elements of the prospect theory - psychology of risky decisions}

The solution described above requires the fulfilment of strict assumptions: players should be fully rational and should mutually expect full rationality from each other. They should also perceive values (and probabilities) objectively and make choices based on real monetary absolute values, as well as assume the competitor's analogous behaviour. This however does not fully comply with the achievements of behavioural finance. People are not fully rational, and their behaviour is defined by many inclinations resulting from psychological and social aspects.

Some of them are described by the prospect theory of Kahnemann and Tversky (1979). Its implementation in the analysis is needed, because the prospect theory describes psychological aspects of the situation modelled within the real options area. The real option approach focuses on the strategic decisions under risk, treated as an opportunity and not only as a threat - while the prospect theory explains the mechanisms of the economic decisionmaking under risk.

The possible subjective perception of real option values is of special importance in the case of real option games, situations of strategic decision flexibility and endogenous competition. Making optimal decisions requires accurate modelling of the competitor's behaviour, including real option value perception. A fully rational player should take into account the competitor's bounded rationality. Including elements of the prospect theory can help to model more properly the value perception under risk, which is crucial in real options games.

The option valuation model consistent with the prospect theory should especially take into account the subjective perception of the probabilities of different future scenarios and the subjective perception of the intrinsic value of an option, interpreted in relation to the reference point. In our model the formula of the value function $v(x)$ of Tversky and Kahnemann (1992) is used:

$$
v(x)=\left\{\begin{array}{rr}
x^{\alpha}, & x \geq R P \\
-\lambda *\left(-x^{\beta}\right), & x<R P
\end{array}\right.
$$

where $x$ is the value of gain (loss), $\alpha$ and $\beta$ are risk tolerance parameters - for gains and losses respectively $-\lambda$ measures loss aversion and $R P$ is the reference point, above (below) which future outcomes are perceived as gains (losses). Also the weighting function $\pi(p)$ is used according to Tversky and Kahnemann (1992):

$$
\pi(p)=\frac{\delta p^{\gamma}}{\left(\delta p^{\gamma}+(1-p)^{\gamma}\right)^{\frac{1}{\gamma}}}
$$

where $p$ is the (objective) probability of a scenario and $\gamma$ is sensitivity to low probabilities. 
The values of the parameters of both functions are used (in further examples) according to their average values assessed by Tversky and Kahnemann (1992): $\alpha=\beta=0.88, \lambda=2.25$, $\gamma^{+}=0.61, \gamma^{-}=0.69^{4}$. It should be mentioned that these parameters result from the individual psychological characteristics of each decision maker. Therefore each subject's perception of values and probabilities is different, so the perceived value of an option should vary between people.

Also the value of the reference point, against which outcomes are classified as gains or losses, results from the characteristics of subjective perception. This can be the level of individual aspirations (Gentry 2006), it can also a result from some historical values, e.g. the level of personal wealth before taking the decision, or from benchmarks from the comparable alternative investments of competitors' activities (Fiegenbaum et al. 1996). The reference point is crucial in the context of real options, which are not traded on the public market, so they are more directly related to the individual psychological characteristics of an investor.

Because of the assumption of subjective value and probabilities perception (bounded rationality), the no-arbitrage assumption has to be released. As a consequence, the riskadjusted rate of return $r$ and real probabilities of future scenarios have to be used ( $p(1-p)$ for the increase (decrease) in the underlying instrument value).

The value of a real option $C_{0}$ is the cash equivalent of future benefits from holding an option. It is the value of a loan, which the investor should take in order to get the same subjective utility as in the case of holding an option. It is equivalent to the formula:

$$
v\left(C_{0} \times(1+r)-R P\right)=\pi(p) \times v\left(C_{u}-R P\right)+\pi(1-p) \times v\left(C_{d}-R P\right)
$$

where $C_{u}$ and $C_{d}$ are intrinsic values of the option in the next period.

As the no-arbitrage assumption is released, the risk-adjusted rate of return $r=0.2$ and real probabilities of future scenarios $p=1-p=0.5$ are used. Leaving all other assumptions unchanged (caeteris paribus), giving up the no-arbitrage assumption would result in the payoffs presented below. The full rationality and common knowledge assumptions are still valid, for now. The only difference is using real probabilities and a risk-adjusted rate of return ${ }^{5}$.

In this case, within pure strategies there are two combinations in period 0 satisfying the conditions of Nash equilibriums: simultaneous investment and the waiting of both players. If one of them decides to wait, the option value of his/her competitor $(20.8=(0.5 \times 50+$ $0.5 \times 0) /(1+0.2))$ is higher than the value that could be earned when investing alone $(20=$ $100-80$ ). Otherwise, the payoff from the simultaneous investment NPV $=10$ is higher than zero - the payoff from waiting. The solution to the option game example would be therefore

\footnotetext{
${ }^{4}$ Kahnemann and Tversky distinguish between $\gamma^{+}$for gains and $\gamma^{-}$or losses.

${ }^{5}$ This is in accordance with the dynamic programing approach presented by Dixit and Pindyck (1994: 93-130).
} 
a mixed equilibrium. The mixed strategy that would be chosen by the players would be waiting with the probability of $0.92(=(0-10) /(20-10+0-20.8))$ and investing with the probability of 0.08 . The expected payoff from this strategy is $19.2(=0.92 \times(0.92 \times 20.8+$ $0.08 \times 0)+0.08 \times(0.92 \times 20+0.08 \times 10))$.

PERIOD 0

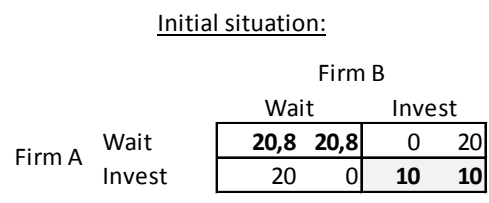

PERIOD 1

High demand:

Firm B

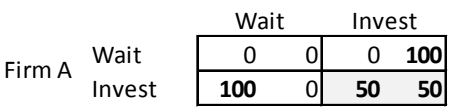

Low demand:

Firm B

\begin{tabular}{ll|rr|rr|}
\multicolumn{2}{c}{} & \multicolumn{2}{c}{ Wait } & \multicolumn{2}{c}{ Invest } \\
\cline { 2 - 5 } Firm A & Wait & $\mathbf{0}$ & $\mathbf{0}$ & $\mathbf{0}$ & -20 \\
\cline { 3 - 6 } & Invest & -20 & $\mathbf{0}$ & -10 & -10 \\
\cline { 3 - 5 } & & & &
\end{tabular}

Figure 2. Players' payoffs in the exemplary option game after releasing the no-arbitrage assumption

Source: authors' own.

Implementing elements of the prospect theory can result in different values perceived by players. While the cash equivalents of sure payoffs do not change, the option values can vary. In the case of real options future benefits are risky ${ }^{6}$. As a result, future benefits can represent different utility (subjective value) for the players, depending on their value function parameters, and resulting in different monetary equivalents. Also the subjective probabilities (weights) can differ from objective ones, influencing the value of cash equivalents. As a consequence, monetary equivalents representing the value of holding the exemplary option can differ from those previously described.

As an example, it can be assumed that player B is not fully rational, and his/her perception of values and probabilities can be described by the prospect theory, using the formulas described before. Moreover, the parameters of value and weighting functions can be described by the average values assessed by Tversky and Kahnemann (1992). Let the exemplary reference point of player $\mathrm{B}$ be equal to $\mathrm{RP}=20$. The option value would depend on the solution to subgames in period 1. Assuming that they did not change, the intrinsic value of an example option to defer perceived by player B would be:

\footnotetext{
${ }^{6}$ Especially if both future profits and losses in relation to the reference point can be expected.
} 


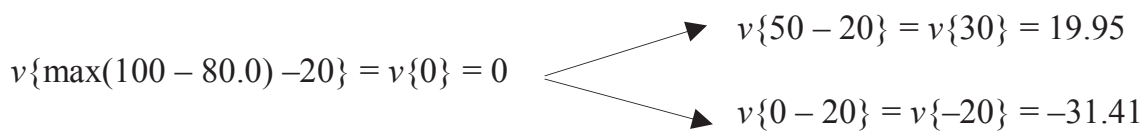

Figure 3. The perceived intrinsic value of the exemplary option to defer

Source: authors' own.

Consequently, the option value to player B would be 14.25 , because this is the only amount whose future value (capitalised at the rate of return $r=0.2$ ) - equation (4) - would allow him to achieve the same level of utility as when owning a real option - equation (4a):

$$
\begin{gathered}
v\left(C_{0} \times(1+r)-R P\right)=v(14.25 \times(1+20 \%)-20)=v(-2.84)=-5.73 \\
\pi(p) \times v\left(C_{u}-R P\right)+\pi(1-p) \times v\left(C_{d}-R P\right)=50 \% \times 10.95+50 \% \times(-31.41)=-5.73
\end{gathered}
$$

Because of the individual perception of values and probabilities, psychological differences between players can have an impact on payoffs distribution, leading to different solutions to subgames, and influencing the value of shared real options. What is more, releasing the full rationality assumption would lead to a different way of finding the equilibrium, examined within the area of the behavioural game theory (Camerer et al. 2004).

The behavioural game theory is a combination of the traditional game theory and empirical investigation of real strategic behaviour. This includes, among others, examining preference interdependence ${ }^{7}$ and the way how players model other players' behaviour. The traditional game theory assumes that people can perfectly predict others players' decisions. Nash equilibrium is established if someone chooses the decision that is best for oneself, having correct expectations about others' decisions. In reality, his/her beliefs can be and often are wrong and the way players choose strategies is not fully rational. The behavioural game theory tries to model people's real way of thinking and learning in strategic situations. This includes, among others, finding the first combination of players' actions as well as modelling the actual learning iterations. As far as in the case of repeated games a learning process can occur, leading to some equilibrium close to the rational one, one-shot games exclude iterative learning approximations. Meanwhile, they are very common in the real world, including most of the real options.

However, the behavioural game theory is an insufficiently exploited area offering no generally accepted and commonly recognized models. Therefore, it is crucial to emphasize that we do not take up the challenge of finding the final solutions to the exemplary games in the world of bounded rationality. The aim of this article is only to discuss the influence of a different perception of values and probabilities on the payoffs distribution, rather than to find the solution to the presented option games. Undoubtedly, finding the way how players

\footnotetext{
${ }^{7}$ They include reciprocity like altruism or envy.
} 
finally make their strategic decisions in the world of decision-making flexibility and competition would be another very important area worth further investigation.

Many models of people's behaviour in one-shot games characterize players with the number of (backward) steps of iterated thinking that subjects make ${ }^{8}$, leading to the solution of the initial play. Researchers empirically find this number, describing it as the index of bounded rationality. Regardless of its value, what is crucial for players' choice of strategies are a few backward steps of the competitor's perception analysis.

Player's expectations about the competitor's payoffs depend on the beliefs about whether the competitor is fully rational and how he/she perceives values and probabilities. Each player takes a decision based on his/her conviction about the other player's behaviour, formulated ex ante. If player A is fully rational and player B is not, player B can by unaware of player A's full rationality. A fully rational player should take into account player B's real way of thinking. Only thanks to the right modelling of player B's behaviour can player A make optimal decisions, properly anticipating the competitor's actions. He/she should accurately foresee what player B thinks about player A's and player B's (his/her own) perception he/she could have incorrect beliefs in both regards. Player A should also properly model player B's convictions about both players' beliefs with regard to each competitor's perceptions. Furthermore, he/she should model B's beliefs of both players' assumptions with regard to each competitor's convictions about the other's perceptions etc. In the case of the classical game theory, all these cases are described by full rationality assumptions, which is hardly ever the case in real life. What is more, the behavioural game theory limits the number of iterated steps of backward thinking modelled by players.

For example, if player A perceives the values and probabilities as described before (full rationality) and player B's perception can be described by the exemplary value and weighting functions (bounded rationality), the payoffs would be as follows (level 1 in cognitive backward thinking). These values were calculated for B's exemplary reference point equal to 20. For reasons of comparability, the values presented below are monetary equivalents - in the case of both present values of payoffs and values of a (real) option to defer the investment.

${ }^{8}$ See level- $k$ (Costa-Gomes et al. 2001), quantal level- $k$ (Stahl, Wilson 1994), cognitive hierarchy (Camerer et al. 2004), quantal response equilibrium (McKelvey, Palfrey 1995), bond equilibrium (Wright, Leyton-Brown 2010). 
PERIOD O

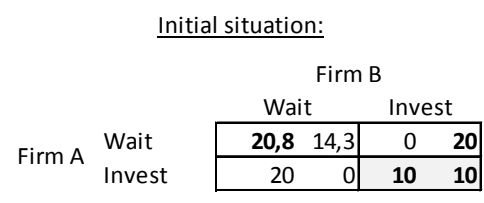

PERIOD 1

High demand:

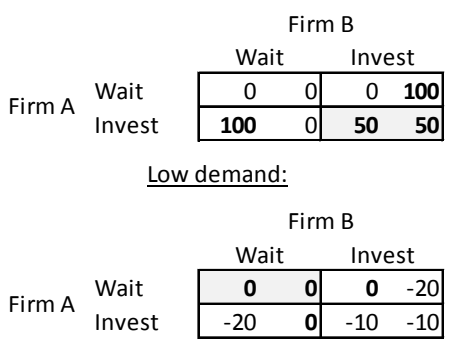

Figure 4. Values perceived by players A (full rationality) and B (bounded rationality)

Source: authors' own.

The payoffs in the subgames presented above can result in a different solution to the option game than was the case before. Especially in period 0 the new payoffs distribution can provoke simultaneous investment. Assuming the same outcome of subgames in period 1 as described before, the value of waiting (option value measured by a monetary equivalent) for player B is 14.3 , so it is lower than the value that could be earned if only player B invested (20). This could lead to simultaneous investment by both players.

Moreover, player B can have unrealistic beliefs in relation to his/her own value perception as well as his/her competitor's perceived values of payoffs (level 2 in the cognitive backward thinking modelling). For instance, player B assumes A not to be fully rational (although in reality player A is fully rational). Player B assigns to player A the same parameters of value and weighting functions as his/her own and the reference point equal to 10 . As a consequence, the option value perceived by A, according to B's beliefs, would be 12.8, i.e. lower than 20, which could be earned in the case of independent investment. This could finally lead to a different subgame equilibrium, increasing the probability of simultaneous investment (Figure 5).

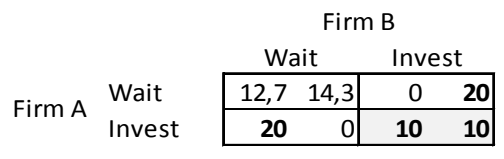

Figure 5. Player B's convictions about the payoffs perceptions of players A and B (period 0)

Source: authors' own.

What is more, player B could have unrealistic convictions about player A's beliefs. Payer $\mathrm{B}$ may think that $\mathrm{A}$ is convinced that neither of the players is fully rational. For reasons of simplicity, let us assume that he/she assumes that A assigns to both players the same 
parameters as those used before. The only difference is the value of the reference points: equal to 10 for both players. The payoffs supposedly assigned by A to both players are shown in Figure 6.

Player B's assuming such payoffs prediction of player A could lead to B choosing the strategy of investing, as far as he/she could expect the same from his/her competitor. Because B would expect that A would choose to invest, he/she would compare his/her monetary equivalents in only two scenarios: only B investing or simultaneous investment (14.3 and 20 respectively $^{9}$ ) - where the latter is higher.

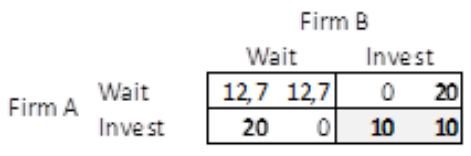

Figure 6. Player B's convictions about player A's beliefs about players' payoffs perceptions (period 0)

Source: authors' own.

On the other hand, another situation could occur: if player B thinks that player A assumes the reference point of both players was equal to -30 , the payoffs expected by him/ her from both players (monetary equivalents) would be as shown in Figure 7. If the real reference point of player B was -20 , and player A was fully rational, the real expectation (monetary equivalents) of both players would be like those in Figure 8.

\section{Firm B}

\begin{tabular}{llrr|rr|} 
& \multicolumn{2}{c}{ Wait } & \multicolumn{2}{c}{ Invest } \\
\cline { 3 - 6 } Firm A & Wait & Invest & $\mathbf{2 0 , 2}$ & 0 & $\mathbf{2 0}$ \\
\cline { 3 - 6 } & Invest & & $\mathbf{1 0}$ & $\mathbf{1 0}$ \\
\cline { 3 - 5 } & & & &
\end{tabular}

Figure 7. Player B's convictions about player A's beliefs of the payoffs perceptions of player B (period 0)

Source: authors' own.

Firm B

\begin{tabular}{|c|c|c|c|c|c|}
\hline & \multirow{4}{*}{$\begin{array}{l}\text { Wait } \\
\text { Invest }\end{array}$} & \\
\hline \multirow{3}{*}{ Firm A } & & \multicolumn{2}{|c|}{ Wait } & \multicolumn{2}{|c|}{ Invest } \\
\hline & & 20,2 & 20,1 & c & 20 \\
\hline & & 20 & 0 & 10 & 10 \\
\hline
\end{tabular}

Figure 8. Players' real monetary equivalents (period 0)

Source: authors' own.

\footnotetext{
${ }^{9}$ Player A's real monetary equivalent is 14.7 , as described before.
} 
This could in turn lead to a higher probability of player B waiting. In the case of player B's choosing the strategy to wait, player A's monetary equivalent from waiting, expected by player B, is higher than the one from investing (20.2 and 20 respectively), which was not the case in the previous example. Because the probability of player A's waiting is higher, in player B's perception, B could also choose the same strategy.

Even if it was not our objective to find the solution to these examples, the core problem was illustrated: the perception of values and probabilities as well as beliefs about the competitor's perception can have an impact on players' choice of strategies and, in consequence, on the shared option value.

\section{Concluding remarks}

The article contains proposals of a real option games analysis including elements of the prospect theory. Drawing on the achievements of behavioural finance, a fully rational player should assume the other player's bounded rationality in order to make optimal decisions and properly assess the real shared option value. This concerns the real way of making the decisions under risk.

Because the perception of values and probabilities results from people's individual psychological characteristics, perceived subjective option values can vary between players. Parameters of value and weighting functions and each player's reference point can influence the payoffs. They, in turn, can have an impact on the solutions to subgames and the shared option value.

There are many undiscovered areas posing new research challenges related to the subject discussed in this article. Because of their multiplicity, only a sample of them will be presented. One of these challenges is the proposed simplified model of option valuation including the value and weighting function. The simple binominal CRR model can assume too simplistic or too unrealistic, a perception of future volatility. Another question is the accessibility of information as well as deepening the editing stage. It should be investigated how players map payoffs distribution - both their own payoffs and others'. This concerns first of all financial parameters of the option valuation model, but also players' psychological characteristics expressed by value and weighting functions parameters and the reference point value. A huge, not fully discovered, area is the behavioural game theory. "What are the solutions to one-shot games?", and "How does the learning and thinking process work in reality?" - these are some crucial questions for proper modelling or real option games. Especially the analysis of successive steps of iterated thinking, together with assumptions about the competitor's level of rationality and his/her perception, plays a significant role in proper option games modelling. As far as options introduce some dynamics, the evolution over time of all the processes mentioned can be of special importance as well.

The purpose of this article was to initiate a discussion about the implications of behavioural finance achievements for real option games and shared options valuation. We hope 
that our joint future research will help to explore strategic decision interactions in a dynamic world.

\section{References}

Camerer C.F., Ho T-H., Kuan Chong J. (2004), Behavioral Game Theory: Thinking, Learning, and Teaching, in: Advances in Understanding Strategic Behaviour. Game Theory, Experiments and Bounded Rationality, ed. S. Huck, Palgrave Macmillan, Basingstoke.

Costa-Gomes M., Crawford V., Broseta B. (2001), Cognition and Behaviour in Normal-Form Games: An Experimental Study, "Econometrica” vol. 69, no. 5, pp. 1193-1235.

Cox J.C., Ross S.A., Rubinstein M., (1979), Option Pricing: A Simplified Approach, "Journal of Financial Economics" no. 7, pp. 229-263.

Dixit A., Pindyck R. (1994), Investment under Uncertainty, Princeton University Press, New Jersey.

Fiegenbaum A., Stuart H., Schendel D. (1996), Strategic Reference Point Theory, "Strategic Management Journal" vol. 17, no. 3, pp. 219-235.

Gentry R.J (2006), Aspirations and Real Options: a Behavioral Theory of Strategic Decision Making, PhD dissertation, University of Florida.

Grenadier S.R. (2002), Option Exercise Games: An Application to the Equilibrium Investment Strategies of Firms, "The Review of Financial Studies" vol. 15, no. 3, pp. 691-721.

Kahnemann D., Tversky A. (1979), Prospect Theory: An analysis of Decision Under Risk, "Econometrica" vol. 47, no. 2, pp. 263-292.

McKelvey R., Palfrey T. (1995), Quantal Response Equilibria for Normal Form Games, "Games and Economic Behavior" vol. 10, no. 1, pp. 6-38.

Myers S. (1977), Determinants of Corporate Borrowing, "Journal of Financial Economics” no. 5, pp. 47-175.

Nash J., (1950), Equilibrium points in n-person games, Proceedings of the National Academy of Sciences, vol. 36, no. 1, pp. 48-49.

Smit H.T.J., Ankum L.A. (1993), A Real Options and Game-Theoretic Approach to Corporate Investment Strategy under Competition, "Financial Management" vol. 22, no. 3, pp. 241-250.

Smit H.T.J., Trigeorgis, L. (2004), Strategic Investment: Real Options and Games, Princeton University Press, New Jersey.

Smit H.T.J., Trigeorgis L. (2006), Real options and games: Competition, alliances and other applications of valuation and strategy, "Review of Financial Economics" vol. 15, pp. 95-112.

Stahl D., Wilson P. (1994), Experimental ecidence on players' models od other players, "Journal of Economic Behavior \& Organization" vol. 25, no. 3, pp. 309-327.

Tallon P. et al. (2002), Using Real Options Analysis for Evaluating Uncertain Investments in Information Technology, "Communications of the Association for Information Systems", pp. 136-167.

Tversky A., Kahnemann D. (1992), Cumulative Representation of Uncertainty, "Journal of Risk and Uncertainty" vol. 2, pp. 297-323.

von Neumann J., Morgenstern O. (1944), Theory of Games and economic Behavior, Princeton University Press, Princeton.

Watson J. (2001), Strategy: An Introduction to Game Theory, W.W. Norton \& Co Inc, New York.

Wright J., Leyton-Brown K. (2010), Beyond Equilibrium: Predicting Human Behavior in Normal Form Games, Proceedings of the Twenty-Fourth AAAI Conference on Artificial Intelligence (AAAI-10).

Zhu K., Weyant J. (2003), Strategic Excercise of Real Options: Investment Decisions in Technological Systems, "Journal of Systems Science and Systems Engineering" vol. 12, no. 3, pp. 257-278. 


\section{ELEMENTY TEORII PERSPEKTYWY W PODEJŚCIU OPCYJNYM DO ANALIZY GIER STRATEGICZNYCH}

Streszczenie: $\mathrm{W}$ artykule przedstawiono propozycję podejścia do analizy opcji rzeczywistych w kontekście teorii gier, uwzględniającą elementy teorii perspektywy. Zakłada się ograniczoną racjonalność konkurenta, którego percepcję opisano funkcją oceny i funkcją ważącą. Problem zilustrowano przykładami liczbowymi. Artykuł inicjuje dyskusję dotyczącą konsekwencji dorobku finansów behawioralnych dla analizy opcji rzeczywistych oraz wyceny opcji współdzielonych.

Slowa kluczowe: opcje realne, teoria gier, teoria perspektywy, finanse behawioralne

\section{Citation}

Jarzęcki M., Mizerka J. (2015), Elements of the Prospect Theory in Strategic Investment Games, Zeszyty Naukowe Uniwersytetu Szczecińskiego nr 855, „Finanse, Rynki Finansowe, Ubezpieczenia” nr 74, t. 1, Wydawnictwo Naukowe Uniwersytetu Szczecińskiego, Szczecin, s. 433-446; www.wneiz.pl/frfu. 